\title{
Deriving Principles of the Freeze-Foaming Process by Nondestructive CT Macrostructure Analyses on Hydroxyapatite Foams
}

\author{
Matthias Ahlhelm ${ }^{1, *}$, David Werner ${ }^{1}{ }^{\mathbb{D}}$, Nils Kaube ${ }^{2}$, Johanna Maier ${ }^{2}$, Johannes Abel ${ }^{1}$, \\ Thomas Behnisch ${ }^{2}$, Tassilo Moritz ${ }^{1}{ }^{\circledR}$, Alexander Michaelis ${ }^{1}$ and Maik Gude ${ }^{2}$ \\ 1 Fraunhofer Institute for Ceramic Technologies and Systems, IKTS, Winterbergstraße 28, 01277 Dresden, \\ Germany; david.werner@ikts.fraunhofer.de (D.W.); johannes.abel@ikts.fraunhofer.de (J.A.); \\ tassilo.moritz@ikts.fraunhofer.de (T.M.); alexander.michaelis@ikts.fraunhofer.de (A.M.) \\ 2 Institute of Lightweight Engineering and Polymer Technology, Technische Universität Dresden, Holbeinstr. 3, \\ 01307 Dresden, Germany; nils.kaube@mailbox.tu-dresden.de (N.K.); johanna.maier@tu-dresden.de (J.M.); \\ thomas.behnisch@tu-dresden.de (T.B.); maik.gude@tu-dresden.de (M.G.) \\ * Correspondence: matthias.ahlhelm@ikts.fraunhofer.de; Tel.: +49-351-2553-7572
}

Received: 2 May 2018; Accepted: 8 June 2018; Published: 17 June 2018

check for updates

\begin{abstract}
Freeze Foaming is a direct foaming method that aims at manufacturing ceramic cellular scaffolds for diverse applications. Next to porous structures for a potential use as refractories, the focus lies on potential bone replacement material. The main challenge of this foaming method is to achieve a homogeneous and predictable pore morphology. That is why, in a current project, the authors report on the pore morphology formation and evolution of the foaming process by means of nondestructive testing. This contribution primarily compares the effect of the suspension's temperature on the resulting foam structure (foaming at 5 and $40{ }^{\circ} \mathrm{C}$ ). As a basis for computed tomographic analysis, a stable and reproducible model suspension was developed that resulted in reproducible foam structures. Characterized by viscosity, foam structure analyses and foaming rate, the resulting Freeze Foams became adjustable with regards to their porosity and pore shape/size. Under certain conditions, we succeeded in achieving a relatively homogeneous pore structure, as proven by computed tomography-derived quantitative analysis.
\end{abstract}

Keywords: Freeze Foaming; bioceramics; foaming process; computed tomography; none destructive testing; cellular ceramics

\section{Introduction}

\subsection{The Freeze-Foaming Process and Recent Achievements}

The Freeze-Foaming process can be classified into direct foaming methods in which suspensions are foamed either by turbulent mixing with surfactants [1] or by in situ gas and vapor developing reactions [2,3]. The two other industrially relevant techniques are based on polyurethane (PU) foam replication, i.e., the Replica/Schwartzwalder approach [4], and pore forming substances, e.g., polymeric beads, starch, carbon black, wax or sawdust [5,6]. Polymeric scaffolds and pore formers later need to be burned out in order to achieve the desired porous body. No burnout of organic volatile pore formers and polymer scaffolds is needed with so-called Freeze Foaming, which allows the direct foaming of almost any desired material (diverse ceramics, metals, etc.) as long as it can be prepared as an aqueous suspension. The Freeze-Foaming process is triggered by ambient pressure reduction of an aqueous suspension in a freeze dryer. The applied vacuum initiates an inflation of the suspension medium by rising processing air and water vapor. During this foaming step, only a couple 
of seconds long, the Freeze Foam's macroporosity evolves (foam cell development). Further foaming takes place with the aqueous system moving along the vapor-liquid equilibrium line towards the triple point (referring to the $\mathrm{p}, \mathrm{T}$-diagram of water). After crossing the triple point, the generated protofoam instantaneously freezes and dries via sublimation $[7,8]$. This freezing step can result in cryogenic structures (discussed in more detail in [9]) similar to typical freeze cast structures [10,11] and accounts for the microporosity of foamed structures. Therefore, the Freeze Foam's only pore formers are rising bubbles of processing air and water vapor as well as sublimated frozen water. After debindering and sintering, the particularly typical ceramic properties can be achieved.

The manifold possibilities concerning material choice and, up until now, basic opportunities to tune the overall porosity of Freeze Foams, allowed the development of potential insulating refractory bricks made of mullite. It has been shown that, by altering the amount of binder, surfactant, solid content and suspension temperature, a different pore morphology as well as different thermomechanical characteristics can be achieved [12]. The conclusion had been reached that manufacturing refractory bricks by this method is within reach. Although only at a small batch scale, especially near net shaped complex structures (Figure 1) were obtained. Further research has been undertaken concerning the material composition, but adjustment of the optimal pore size is the most crucial variable for sophisticated application.
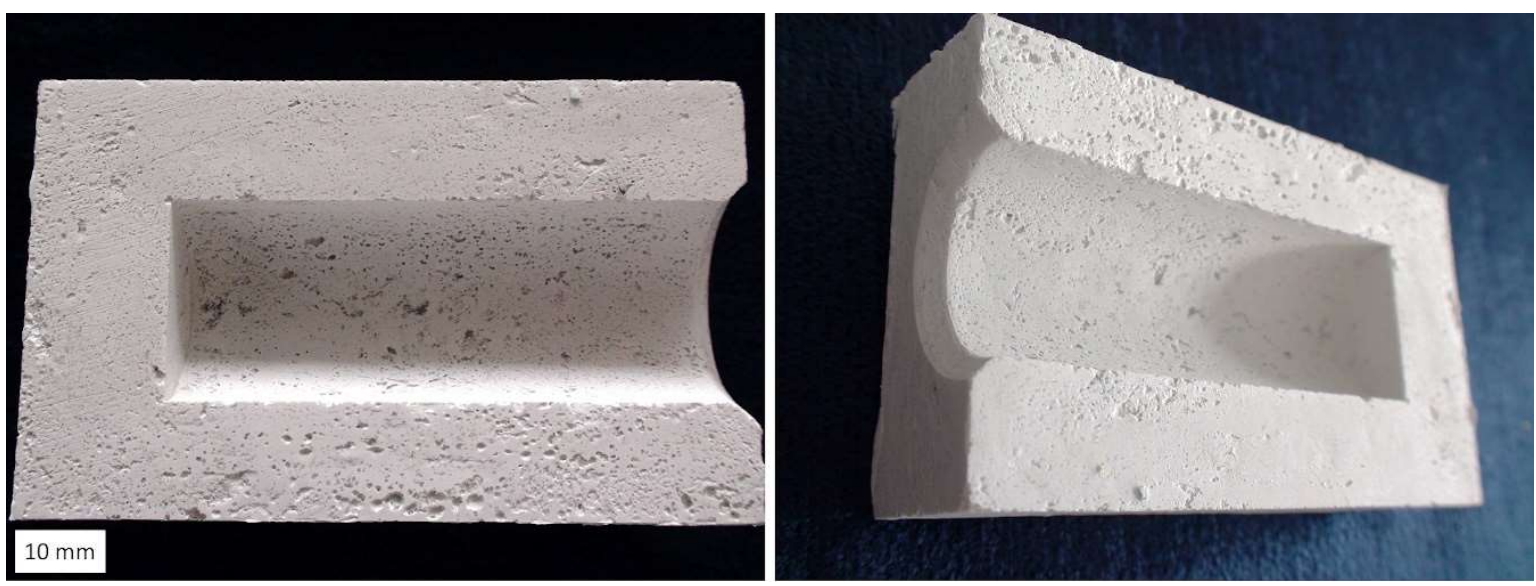

Figure 1. Near net-shaped mullite refractory brick by Freeze Foaming.

The main interest, though, lies in the sector of biomedical technology. With changing the material to bioceramics, the field of synthetic implants and bone replacement material is being addressed. Mainly open porous and interconnected cellular structures have been achieved, which are applicable as biocompatible components when made of hydroxyapatite (HAp), $\mathrm{ZrO}_{2}$ or a composite mixture [13-15]. Recent research is concerned with a hybrid shaping method: First, three-dimensional, complex-shaped hollow shell geometries are manufactured, for instance by Additive Manufacturing processes. In a second step, those shell structures are filled with a ceramic suspension with the Freeze-Foaming process commenced in situ. That process allows for connecting porous/cellular features provided by the Freeze Foaming with the dense and complex features provided by 3D printing methods like LCM (Lithography-based Ceramic Manufacturing). Bioactive femoral bone model demonstrators and dense-porous segmental components (Figure 2) were successfully co-sintered to one composite part $[16,17]$. This hybrid shaping technology therefore offers a wide range of application potential for personalized and surface customizable implant structures for application in the field of biomedical technology and engineering.

However, Freeze Foaming and hybrid shaping so far do not exceed the laboratory scale. Upscaling this process requires large batches of reproducible ceramic suspensions. Applications require cellular scaffolds to either have a closed or open as well as often homogeneous pore morphology in order to 
provide the targeted properties in a predictable manner. With regard to refractories, homogeneously distributed small pores of typically closed porosity (in the range of $100 \mathrm{~nm}$ to $1 \mathrm{~mm}$ for proper isolation capability) are required [18]. In contrast, bioceramic scaffolds for bone replacement material require sufficiently large pores (at least 100-500 $\mu \mathrm{m}$ ) for cell attachment [19,20], interconnectivity [21] and microporosity [11], as well a general porosity greater than $40 \%$ [22-24]. Thus, Freeze Foaming indeed allows for producing open and microporous, as well as interconnected scaffolds. From the example in Figure 2, though, it becomes obvious that cellular Freeze Foams are typically heterogeneous. This makes estimations and assessments of the reproducibility of biocompatibility or mechanical strength very difficult.

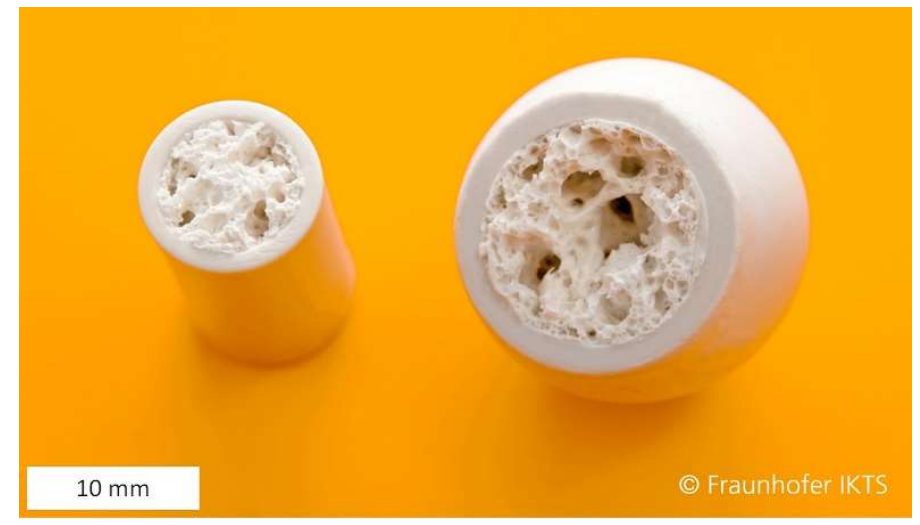

Figure 2. Hybrid manufacturing of combined dense-porous segmental components.

Intense basic research into Freeze Foaming's principles with a consideration of the material and processing aspects is needed. A material preparation and process approach must be found that allows for a controlled tuning of the pore morphology and evaluation of pore evolving activities by monitoring the foaming process itself. One solution that allows insights into processes and influence on materials is being provided by computed tomography (CT), which has become a sophisticated tool for improved damage and degradation analyses as well as structural evaluations in the field of material sciences [25-28].

Already detailed in the previous contribution [9], CT analyses were used for the first time to monitor the Freeze-Foaming process and allow for evaluation of foam structuring phenomena. The first results report the successful manufacturing of a model suspension, of reproducible foam structures foamed at room temperature and the dependence of the porosity, pore size and the shape from the pressure reduction rate of the freeze dryer used. In addition, the first indications of a strong influence of the amount of water with regard to the abundance of occurring cryogenic structures were discovered. The task of the related project's next period was to vary the suspension temperature and monitor the tempered suspension's foaming behavior as well as evaluate the resulting pore morphologies. Reproducible ceramic cellular structures were created with $5{ }^{\circ} \mathrm{C}$ and $40{ }^{\circ} \mathrm{C}$ tempered suspensions. The focus was not on achieving one defined pore size but rather observing and clarifying the phenomena of the Freeze-Foaming process. Since biomaterial application is one of the higher aims, hydroxyapatite was used, which is well known for its similarities to the mineral fraction of bone and its high osteoconductive potential [29-31]. We aimed at reaching a pore size of around 100-700 $\mu \mathrm{m}$ as well as a distribution of pores that was as homogenous as possible. The porosity should be greater than $40 \%$ in order to achieve pore morphologic properties that generally meet the requirements for bone replacement material, as stated above. Since only the green state of manufactured Freeze Foams directly reflects the foaming process's effects on the foam structure, the present contribution focuses on green-state ceramic material only. Analyses of the debinded and sintered foams will follow as soon as the results are available. 


\section{Materials and Methods}

Hydroxyapatite (Sigma-Aldrich now Merck KGaA, Darmstadt, Germany; BET = $70.01 \mathrm{~m}^{2} / \mathrm{g}$, $\left.\mathrm{d}_{50}=2.64 \mu \mathrm{m}\right)$ was chosen as the raw material. The ceramic suspensions consist of water, Dolapix CE 64 (Co. Zschimmer \& Schwarz Mohsdorf GmbH \& Co. KG, Burgstädt, Germany) as dispersing agent, the ceramic powder, polyvinyl alcohol as binder and a rheological modifier (Tafigel PUR40, Co. Münzing Chemie $\mathrm{GmbH}$, Heilbronn, Germany). The following processing route was conducted: Deionized water was mixed manually with 2 vol \% dispersing agent. Subsequently, hydroxyapatite was added (28 vol \%), followed by the polyvinyl alcoholic binder (as 13\% aqueous solution) and 8 vol \% rheological modifier. To pre-mix binder and powder, all components were first stirred manually and afterwards transferred into a centrifugal vacuum mixer (ARV310, Thinky Corporation, Fukuoka, Japan). In order to disperse the particles and reduce agglomeration the mixture was exposed to a high stirring rate $\left(2000 \mathrm{rpm}\right.$, mixing time $2 \times 1 \mathrm{~min}$, with $3 \mathrm{ZrO}_{2}$ mixing spheres of $10 \mathrm{~mm}$ diameter). Afterwards, the suspensions were filled into specific molds and transferred to the freeze dryer (Lyo Alpha 2-4, LSCplus, Co. Martin Christ Gefriertrocknungsanlagen GmbH, Osterode, Germany) for Freeze Foaming.

For achieving Freeze Foams that have been foamed with a $40{ }^{\circ} \mathrm{C}$ tempered suspension, the following sequence was conducted: While mixing the suspension in the vacuum mixer, the foaming molds (cylindrical shape, $14 \mathrm{~mm}$ diameter $\times 20 \mathrm{~mm}$ height) were preheated standing in a closed box, which floated in a $45^{\circ} \mathrm{C}$ tempered water bath. After suspension preparation, each mold was then filled with the same amount of suspension $(2 \mathrm{~g})$ and returned to the preheated and lockable box. After filling (by injection through a die with the same diameter as the cylinder) all rubber molds, they were left in the closed box at $45^{\circ} \mathrm{C}$ water temperature for $40 \mathrm{~min}$ to eventually reach $40{ }^{\circ} \mathrm{C}$ suspension temperature in every mold (measured by a digital thermometer). All molds were then transferred to the freeze dryer and foamed at once. Two thermal elements were used to monitor the suspension temperature throughout the whole foaming process.

For achieving Freeze Foams that have been foamed with a $5^{\circ} \mathrm{C}$ tempered suspension, the rubber molds (same as above) were filled with the ceramic suspension and transferred to a freezing chamber (12 min dwelling time at $-23^{\circ} \mathrm{C}$ ) prior to being foamed in the freeze dryer. Again, two thermal elements were used to monitor the suspension temperature throughout the whole foaming process.

All suspensions were characterized by determining the solid content (moisture measurement: MA 100 Sartorius at $110^{\circ} \mathrm{C}$, Sartorius Lab Instruments GmbH \& Co. KG, Goettingen, Germany) and viscosity (MCR 302, Anton Paar GmbH, Graz, Austria; plate-plate rotation and housing for controlled heat treatment at 5 and $40^{\circ} \mathrm{C}$ ).

For microstructure analysis the resulting Freeze Foams were characterized by SEM (Ultra 55, Co. Carl Zeiss, Oberkochen, Germany).

By measuring the height and diameter on three different foam positions of six Freeze Foams each (foamed at 5 and $40^{\circ} \mathrm{C}$ ) and deriving the average, geometrical porosities were calculated according to:

$$
P=1-\left(\rho_{\text {th }} / \rho_{\text {bulk }}\right)
$$

\subsection{CT Evaluation Procedure}

The following CT-derived results and statements to homogeneity mainly refer to the macropores $(>50 \mu \mathrm{m})$ of Freeze Foams, its foam cells, which are the result of rising air and water vapor. Four green-state foams each obtained from $5{ }^{\circ} \mathrm{C}$ and $40{ }^{\circ} \mathrm{C}$ tempered suspensions were analyzed. Due to resolution restrictions, the apparent micropores are not part of the CT evaluation and rather are detailed in the SEM images. In this subsection we explain how to progress from the reconstructed $\mathrm{CT}$ volume to the defect analysis resulting in porosity and level of interconnection (see results in Section 3.2), followed by the foam structure analysis resulting in pore size and strut thicknesses distribution and directional variability of the foam cell volume (see results in Section 3.2.3). 
For CT a FCTS 160-IS (Fa. FineTec FineFocus Technologies GmbH, Garbsen, Germany) was used, located at the TUD-ILK, Dresden, Germany. The allocation of three-dimensional (3D) volumetric pore morphology information was managed by using VGStudio Max v3.0 (Volume Graphics GmbH, Heidelberg, Germany [32]) allowing access to volume-based data like porosity, pore size distribution and visualization of the foam volume. The CT measurements were performed with the parameters given in Table 1.

Table 1. Parameters for CT measurements.

\begin{tabular}{ccccc}
\hline Tube Voltage & Tube Current & Detector & Voxel Size & Focus Size \\
\hline $40 \mathrm{kV}$ & $180 \mu \mathrm{A}$ & Flat panel detector & $11.7 \mu \mathrm{m}$ & $4 \mu \mathrm{m}$ \\
\hline
\end{tabular}

Using VGStudio Max, we quantified pore morphology data of scanned foams (Figure 3, top left) as also detailed in [9]: First a three-dimensional "Region of Interest" (ROI) is defined and the surface determined by automatic software-assisted grey value analyses (definition of pores, material and material surface; Figure 3, top right). A subsequent defect analysis shows the identified foam cells marked in yellow (Figure 3, bottom left). By multiplying the number of voxels with the grey value belonging to air by the volume of a single voxel, the total volume of defects $\left(V_{\text {def }}\right)$ and the volume of every single identified defect are obtained. Hence, the obtained porosity can be defined as the ratio of $V_{\text {def }}$ to the volume of the ROI $\left(V_{\text {ROI }}\right)$. The level of interconnection among foam cells is represented by the ratio of maximum defect volume $V_{\max }$ and volume $V_{R O I}[25]$.

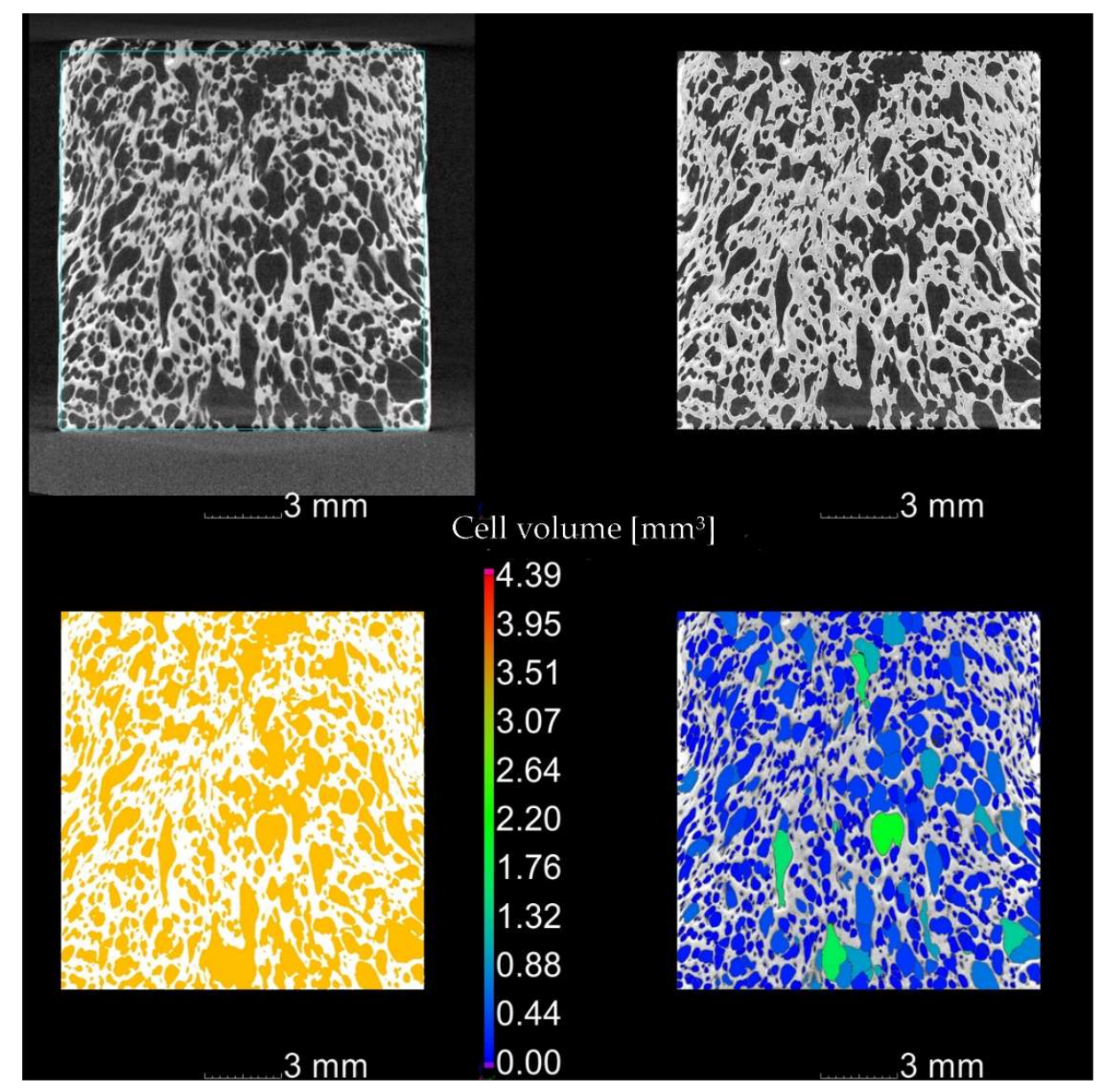

Figure 3. Foam structure analysis procedure on the example of a $5^{\circ} \mathrm{C}$ foamed Freeze Foam. 
As a last step, the foam structure analysis module is used to separate foam cells that are connected by a cell window (Figure 3, bottom right). A high cell volume corresponds to red and a low volume to blue.

Foam structure analysis requires a segmentation threshold. Its determination was carried out as accurately as possible (adjusted so that small pores remain visible and larger pores are not segmented into smaller ones). That allows for first determining the distribution of strut thicknesses and, secondly, the pore size distribution of manufactured Freeze Foams by transforming the resulting foam cell volume $V_{\mathrm{fc}}$ to the equivalent diameter $d$ by the equation:

$$
d=\left(6 V_{\mathrm{fc}} / \pi\right)^{1 / 3}
$$

\subsubsection{Quantifying Foam Homogeneity}

VGStudio Max 3.0 offers an analysis of the directional variability of foam cell volume. That allows us to gain direction-dependent spatial information about the foam cell size-from bottom to top (i.e., in the foaming direction) and from left to right (perpendicular to the foaming direction). Hence, both directions together provide information about the homogeneity of the foam volume.

With this data we carried out a trend analysis by slicing the foam volume into planes perpendicular to the corresponding analysis direction (in the foaming direction or perpendicular to the foaming direction) with a distance of $0.02 \mathrm{~mm}$ from each other. The volume (3D) of all foam cells that lie in the corresponding plane (e.g., $z$ ) is averaged $\left(V_{\mathrm{fc}}(z)\right)$.

We furthermore calculated a parameter for the homogeneity of a Freeze Foam's pore morphology by considering the progression of $V_{\mathrm{fc}}$ as the profile of the foam's pore morphology-specifically, the cell volume-analogously to the roughness of a surface. According to DIN EN ISO 4287 [33], the following steps are executed: First, we determine the midline of the considered pore morphology profile $V_{\mathrm{fc}}(z)$.

With the help of Equation (3)-(Figure 4, solid line)

$$
V_{\mathrm{fc} 0}=V_{\mathrm{fc}}-\left(V_{\mathrm{fc}}^{\min }+V_{\mathrm{fc}}^{\max }\right) / 2
$$

$-V_{\mathrm{fc}}(z)$ is transferred to the actual profile $V_{\mathrm{fc} 0}(z)$. This allows us to calculate the arithmetic average $\mathrm{V}_{\mathrm{fca}}$ of the profile ordinate $V_{\mathrm{fc} 0}$ as a parameter for the homogeneity of Freeze Foams by deriving the absolute value $\left|V_{\mathrm{fc} 0}(z)\right|$ (Figure 4, dotted line) and integrating to:

$$
V_{\mathrm{fca}}=1 / h \int 0 \mathrm{~h}\left|V_{\mathrm{fc} 0}(z)\right| \mathrm{d} z \text {. }
$$

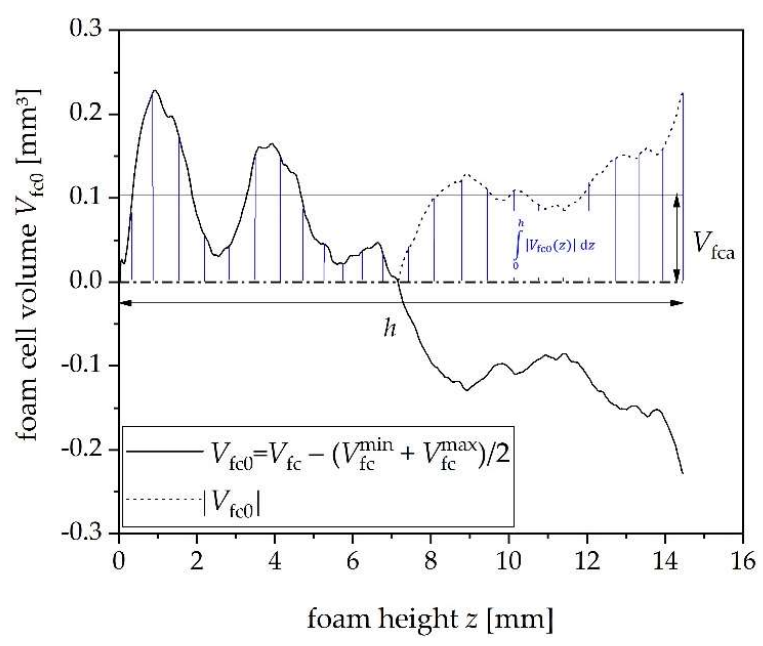

Figure 4. Graph of the arithmetical foam cell's volume average of the profile ordinate. 
A high $V_{\text {fca }}$ corresponds to a large variability in foam cell volume and, hence, stands for a heterogeneous foam structure. In contrast, a low $V_{\mathrm{fca}}$ corresponds to a more homogeneous pore morphology.

\section{Results and Discussion}

\subsection{Reproducibility of Freeze Foams}

According to the procedure depicted in Section 2, suspensions were prepared, tempered and characterized. The following graph (Figure 5) illustrates the viscosity curves of 5 and $40{ }^{\circ} \mathrm{C}$ tempered suspensions (measured with three suspensions each). As expected, the curve at $5{ }^{\circ} \mathrm{C}$ progresses above the $40{ }^{\circ} \mathrm{C}$ curve.

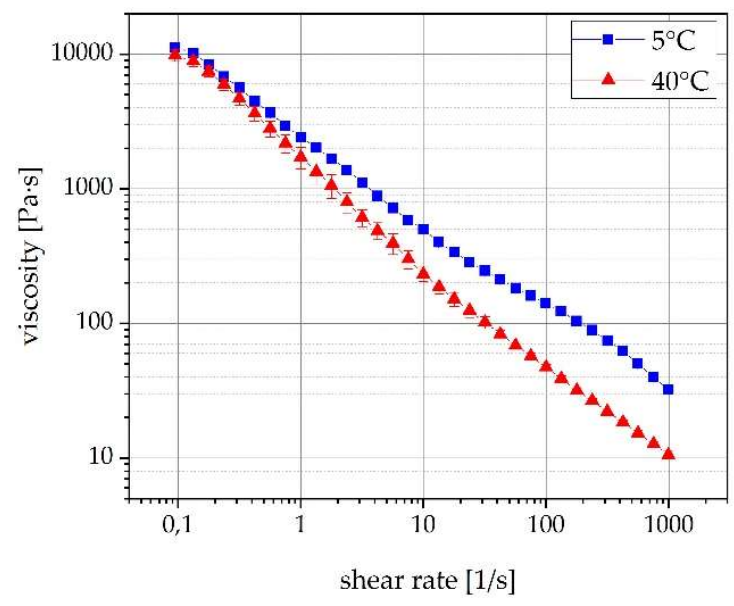

Figure 5. Viscosity of HAp suspensions at 5 and $40{ }^{\circ} \mathrm{C}$ (double logarithmic).

Those suspensions were then used for Freeze Foaming. As a result, we were able to achieve a series of reproducible Freeze Foams foamed at $5{ }^{\circ} \mathrm{C}$ and $40{ }^{\circ} \mathrm{C}$, proven by measurements of solid content and geometrical porosity (Table 2).

Table 2. Reproducibility of suspensions and Freeze Foams (green state). ${ }^{1}$

\begin{tabular}{ccc}
\hline Suspension's Temperature $\left({ }^{\circ} \mathrm{C}\right)$ & Solid Content $(w \mathbf{~ \% )}$ & Geometrical Porosity (\%) \\
\hline 5 & $62.7(\mathrm{SD}=0.7)$ & $81.1(\mathrm{SD}=0.9)$ \\
40 & $63.4(\mathrm{SD}=0.4)$ & $79.9(\mathrm{SD}=1.2)$ \\
\hline
\end{tabular}

${ }^{1}$ Five suspensions, six Freeze Foams each; $\mathrm{SD}=$ standard deviation.

In order to quantify the actual foaming, we introduce the foaming degree $f$ as the quotient from suspension/foam volume at a specific pressure/time $V_{\mathrm{S}}(t)$ divided by the volume $V_{0}$ at the beginning:

$$
f(t)=V_{\mathrm{S}}(t) / V_{0} .
$$

Furthermore, we determined the foaming rate (time derivative of $f(t)$ ). Both parameters are illustrated in Figure 6. For measurements, test glasses were filled with approximately $2 \mathrm{~mL}$ suspension tempered at 5 and $40{ }^{\circ} \mathrm{C}$. Both tempered suspensions were then freeze-foamed in the freeze dryer. The ambient pressure in the freeze dryer was lowered in specific pressure steps and the according volume $V_{\mathrm{s}}(t)$ read from the test glasses followed by calculation of $f(t)$ by Equation (5). Table 3 summarizes the pressure values applied during the Freeze-Foaming process for both tempered suspensions and allows us to evaluate the individual foaming behavior (e.g., maximum foaming rate). 

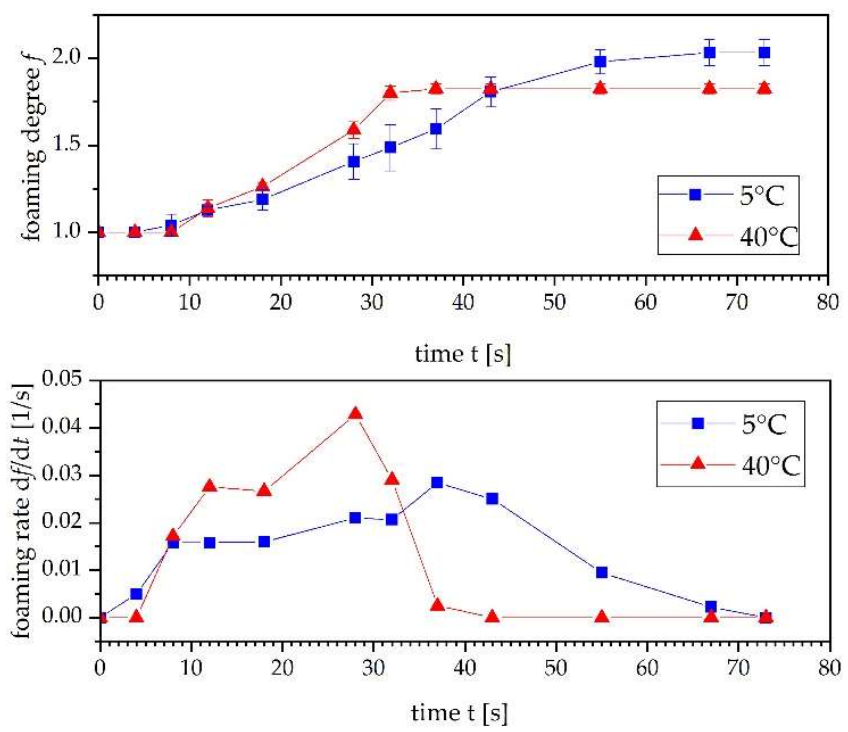

Figure 6. Foaming degree and rate of the Freeze-Foaming process with 5 and $40{ }^{\circ} \mathrm{C}$ tempered HAp suspension.

Table 3. Freeze Foaming pressure values characterizing the foaming behavior. ${ }^{2}$

\begin{tabular}{cccc}
\hline $\begin{array}{c}\text { Suspension's } \\
\text { Temperature }\left({ }^{\circ} \mathrm{C}\right)\end{array}$ & $\begin{array}{c}\text { Pressure at Beginning } \\
\text { of Foaming (mbar) }\end{array}$ & $\begin{array}{c}\text { Pressure at Maximum } \\
\text { Foaming Rate (mbar) }\end{array}$ & $\begin{array}{c}\text { Pressure at end of } \\
\text { Foaming (mbar) }\end{array}$ \\
\hline 5 & 500 & $40-60$ & 10 \\
40 & 400 & $80-100$ & 60 \\
\hline
\end{tabular}

${ }^{2}$ Based on four suspension/Freeze Foams each.

Corresponding to Table 3, Figure 6 also clearly shows that the foaming of $40{ }^{\circ} \mathrm{C}$ tempered suspensions finishes earlier when compared to $5{ }^{\circ} \mathrm{C}$ foamed suspensions (60 vs. 10 mbar). Additionally, it takes place at a much higher rate $(0.0451 / \mathrm{s})$. Suspensions foamed at $40{ }^{\circ} \mathrm{C}$ already reach their maximum after $30 \mathrm{~s}$ (at 80-100 mbar), whereas suspensions foamed at $5{ }^{\circ} \mathrm{C}$ reach their maximum-continuously foaming-after only $70 \mathrm{~s}$ (at 40-60 mbar). The reason for the fast kinetics of the $40{ }^{\circ} \mathrm{C}$ suspension foaming is the increased water vapor partial pressure due to the higher temperature as well as the lower viscosity. The $5{ }^{\circ} \mathrm{C}$ foamed suspensions reach their maximum foaming rate at a low applied pressure due to the higher viscosity and lower water vapor partial pressure (and therefore a lower driving force).

\subsection{Foam Cell Analyses via CT Evaluation}

As detailed at the end of Section 2, the green foams were analyzed via CT at the TUD-ILK and later evaluated with VGStudio Max v3.0 to visualize and quantify pore morphology data of scanned foams.

\subsubsection{Defect Analyses}

The results of the defect analysis are summarized in Tables 4 and 5. The ROI of obtained Freeze Foams covers approximately $95 \%\left(5{ }^{\circ} \mathrm{C}\right.$ foamed) and $87 \%\left(40{ }^{\circ} \mathrm{C}\right.$ foamed), respectively, of the overall foam volume. Therefore, it represents the foam volume well. The calculated mean porosity of $5{ }^{\circ} \mathrm{C}$ foamed structures (Table 4, 53\%) is $5 \%$ higher than $40^{\circ} \mathrm{C}$ foamed samples (Table 5, 48\%). This correlates with the higher foaming degree of $5{ }^{\circ} \mathrm{C}$ observed in Section 3.1 (Figure 6). In comparison with the geometrical porosities of Table 2, the defect analyses-derived porosity is lower. This difference is due to the limitation in CT resolution: micropores were not detected. 
Table 4. Defect analyses of $5{ }^{\circ} \mathrm{C}$ foamed structures. ${ }^{3}$

\begin{tabular}{ccccccc}
\hline & $\mathbf{5}^{\circ} \mathbf{C} \_\mathbf{1}$ & $\mathbf{5}^{\circ} \mathbf{C} \_\mathbf{2}$ & $\mathbf{5}^{\circ} \mathbf{C} \_3$ & $\mathbf{5}^{\circ} \mathbf{C} \_4$ & Mean & SD \\
\hline$V_{\text {foam }}\left(\mathrm{mm}^{3}\right)$ & 2312.41 & 2449.55 & 2371.95 & 2507.32 & 2410 & 86 \\
$V_{\text {ROI }}\left(\mathrm{mm}^{3}\right)$ & 2152.95 & 2350.73 & 2256.80 & 2402.62 & 2291 & 110 \\
$V_{\text {mater }}\left(\mathrm{mm}^{3}\right)$ & 1021.58 & 1084.46 & 1091.48 & 1148.10 & 1086 & 52 \\
$V_{\text {def }}\left(\mathrm{mm}^{3}\right)$ & 1131.37 & 1266.27 & 1165.32 & 1254.52 & 1204 & 66 \\
Porosity $(\%)$ & 52.6 & 53.9 & 51.6 & 52.2 & 53 & 0,9 \\
$V_{\text {max }}\left(\mathrm{mm}^{3}\right)$ & 1125.67 & 1259.81 & 1159.93 & 1247.70 & 1198 & 66 \\
$N$ & 5430 & 6587 & 4826 & 6944 & 5947 & 988 \\
$V_{\text {max }} / V_{\text {def }}(\%)$ & 99.5 & 99.5 & 99.5 & 99.5 & 99.5 & 0.03 \\
\hline
\end{tabular}

${ }^{3} V_{\text {foam }}$ : Geometrically measured volume of Freeze Foams, $V_{\text {ROI }}$ : Volume of the defined ROIs, $V_{\text {mater }}$ : Total volume of material, $V_{\text {def }}$ : Total defect volume (i.e., total foam cell volume), $V_{\max }$ : Maximum defect volume, $N$ : Number of detected defects.

Table 5. Defect analyses of $40^{\circ} \mathrm{C}$ foamed structures. ${ }^{3}$

\begin{tabular}{ccccccc}
\hline & $\mathbf{4 0}{ }^{\circ} \mathbf{C} \_\mathbf{1}$ & $\mathbf{4 0}{ }^{\circ} \mathbf{C} \_\mathbf{2}$ & $\mathbf{4 0}{ }^{\circ} \mathbf{C} \_3$ & $\mathbf{4 0}{ }^{\circ} \mathbf{C} \_4$ & Mean & SD \\
\hline$V_{\text {foam }}\left(\mathrm{mm}^{3}\right)$ & 1836.89 & 1800.82 & 1757.04 & 1884.67 & 1820 & 54 \\
$V_{\text {ROI }}\left(\mathrm{mm}^{3}\right)$ & 1385.70 & 1652.22 & 1614.18 & 1641.88 & 1573 & 126 \\
$V_{\text {mater }}\left(\mathrm{mm}^{3}\right)$ & 667.69 & 868.11 & 834.18 & 917.66 & 822 & 108 \\
$V_{\text {def }}\left(\mathrm{mm}^{3}\right)$ & 718.01 & 784.11 & 780.00 & 724.22 & 752 & 35 \\
Porosity $(\%)$ & 51.8 & 47.5 & 48.3 & 44.1 & 48 & 3,2 \\
$V_{\text {max }}\left(\mathrm{mm}^{3}\right)$ & 714.44 & 778.63 & 775.63 & 719.37 & 747 & 35 \\
$N$ & 6006 & 7177 & 6162 & 5715 & 6265 & 636 \\
$V_{\text {max }} / V_{\text {def }}(\%)$ & 99.5 & 99.3 & 99.4 & 99.3 & 99.4 & 0.09 \\
\hline
\end{tabular}

${ }^{3} V_{\text {foam }}$ : Geometrically measured volume of Freeze Foams, $V_{\text {ROI }}$ : Volume of the defined ROIs, $V_{\text {mater: Total volume }}$ of material, $V_{\text {def }}$ : Total defect volume (i.e., total foam cell volume), $V_{\max }$ : Maximum defect volume, $N$ : Number of detected defects.

With regard to the level of interconnectivity, $5{ }^{\circ} \mathrm{C}$ as well as $40{ }^{\circ} \mathrm{C}$ foamed structures are interconnected to $99 \%$ (Table $4, V_{\max } / V_{\text {def }}(\%)$ ). However, this result is not representative of the permeability of the Freeze Foams because neither the average number of connections to neighboring cells nor the cell window size was determined by VGStudio Max.

\subsubsection{Foam Structure Analyses}

As mentioned in Section 2.1, the segmentation threshold for foam structure analysis was adjusted to be as correct as possible. Figure 7 shows the segmented foam cells. For $5{ }^{\circ} \mathrm{C}$ foamed structures it was adjusted to $50 \%$ (Figure $7 \mathrm{~A}, \mathrm{C}$ ) and for $40{ }^{\circ} \mathrm{C}$ foamed structures to $95 \%$ (Figure $7 \mathrm{~B}, \mathrm{D}$ ). The threshold increase for the $40{ }^{\circ} \mathrm{C}$ foamed structures was necessary because their very irregular foam cells would have been segmented otherwise.

Figure 8 shows the results of the foam structure analysis exerted on the struts. Highlighted in rainbow colors are the struts of the $5{ }^{\circ} \mathrm{C}$ foamed structures (Figure $8 \mathrm{~A}, \mathrm{C}$ ) and the $40{ }^{\circ} \mathrm{C}$ foamed structures (Figure 8B,D). Thin struts are marked in blue, with thicker struts in yellow to red. Quantitative data are represented in Figure 9 (right-hand side) and Table 6. 


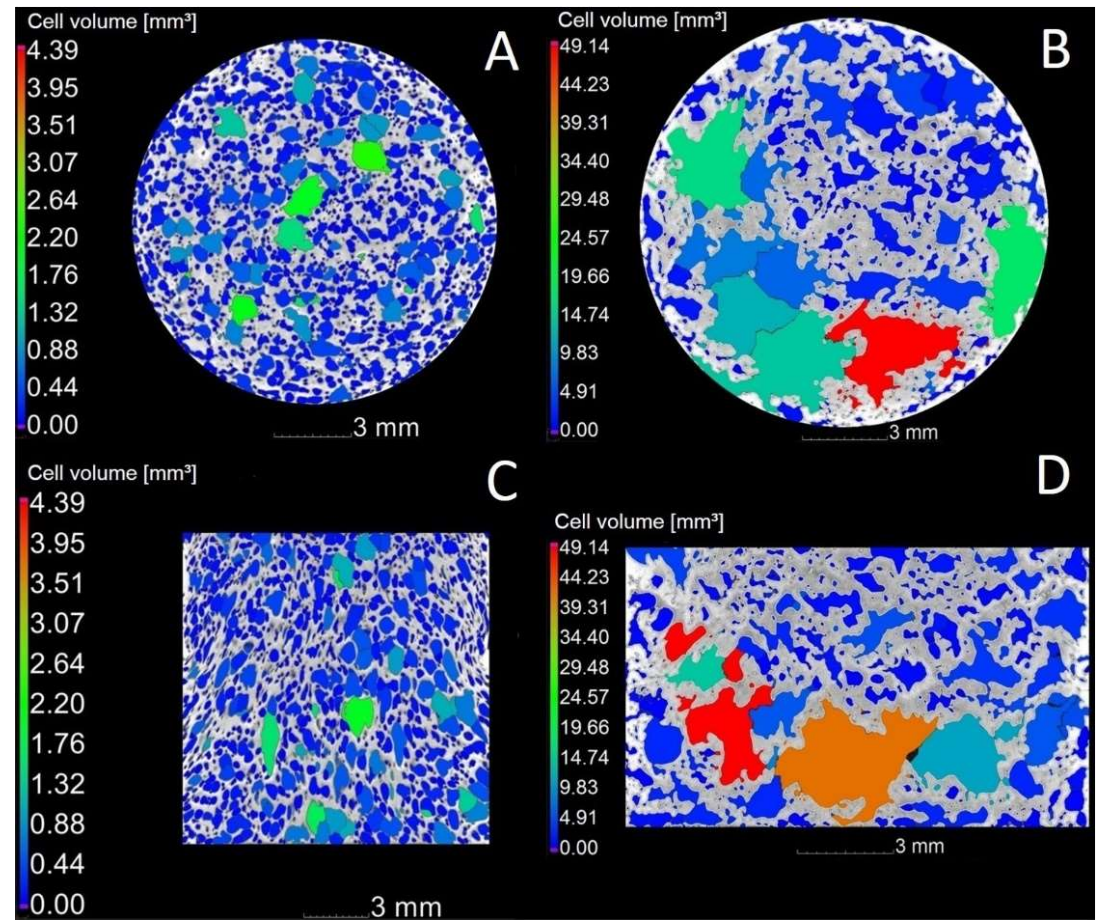

Figure 7. Foam cell segmentation by foam structure analysis module of VGStudio Max 3.0 on the example of $z$-plane $(\mathbf{A}, \mathbf{B})$ and $x$-plane $(\mathbf{C}, \mathbf{D})$ slice images of $5{ }^{\circ} \mathrm{C}(\mathbf{A}, \mathbf{C})$ and $40{ }^{\circ} \mathbf{C}(\mathbf{B}, \mathbf{D})$ foamed structures. Slices are taken from the middle of the foam volume. Segmentation threshold for $5{ }^{\circ} \mathrm{C}$ foams is $50 \%$ and for $40{ }^{\circ} \mathrm{C} 95 \%$.

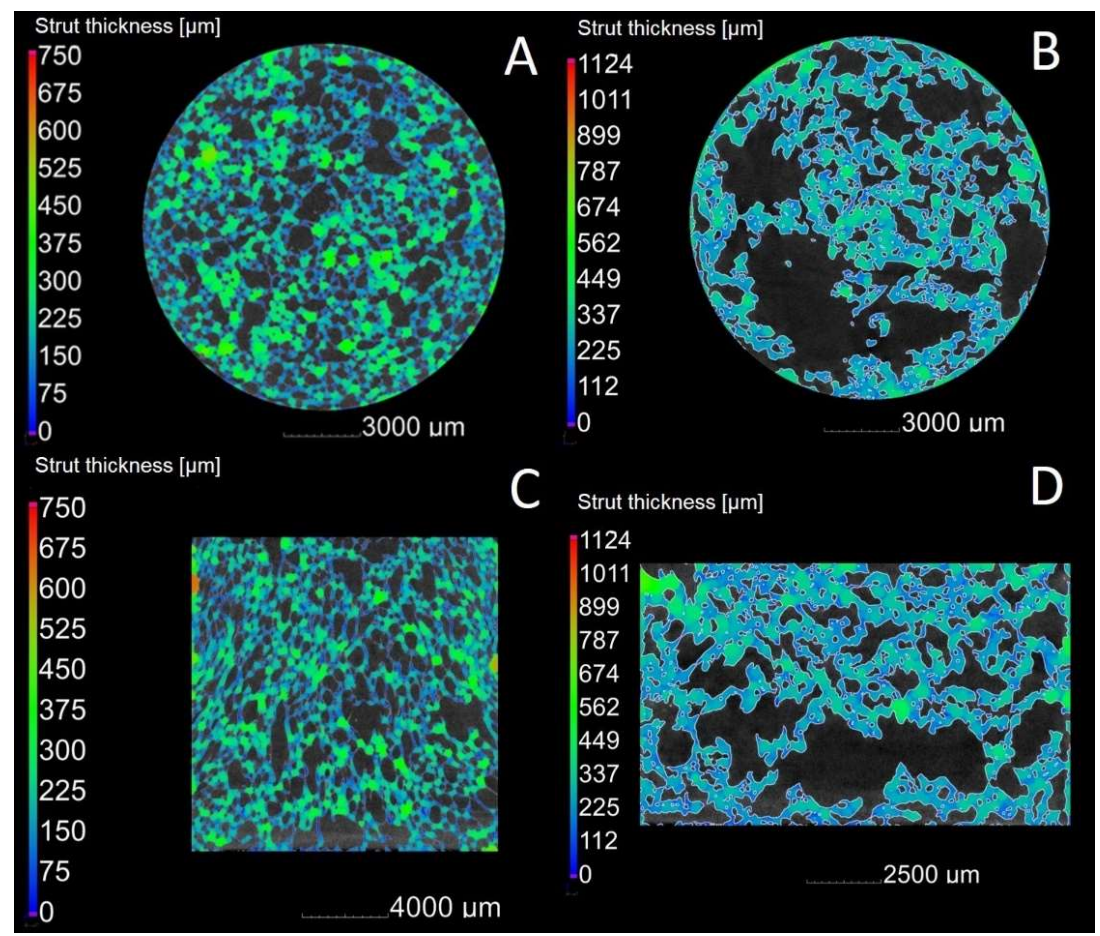

Figure 8. Strut thickness calculated by foam structure analysis module of VGStudio Max 3.0 on the example of $z$-plane $(\mathbf{A}, \mathbf{B})$ and $x$-plane $(\mathbf{C}, \mathbf{D})$ slice images of $5{ }^{\circ} \mathrm{C}(\mathbf{A}, \mathbf{C})$ and $40{ }^{\circ} \mathbf{C}(\mathbf{B}, \mathbf{D})$ foamed structures. Slices are taken from the middle of the foam volume. 


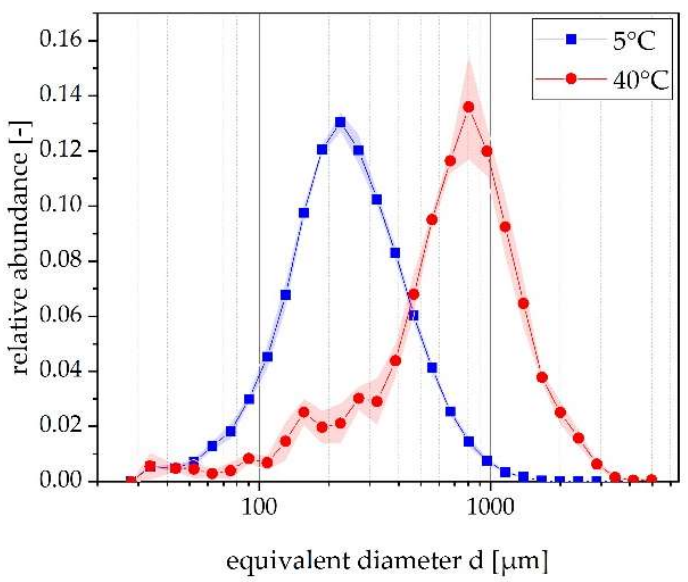

(A)

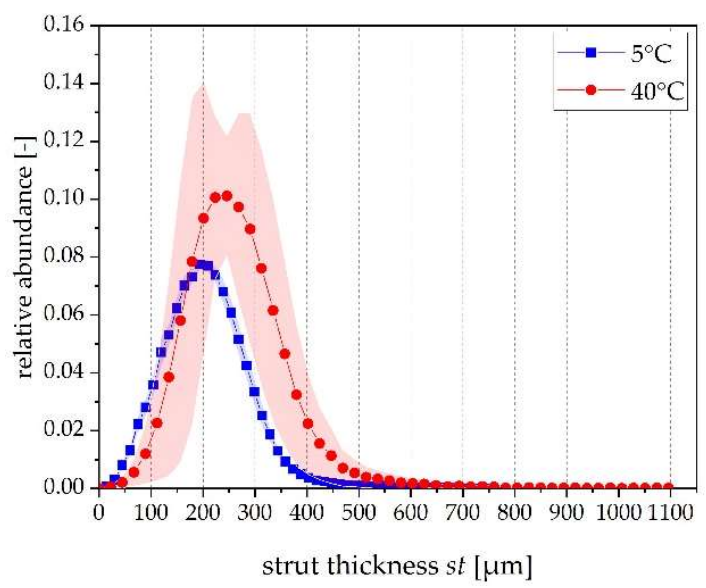

(B)

Figure 9. Pore size distribution (A) and distribution of strut thickness (B) of $5{ }^{\circ} \mathrm{C}$ and $40{ }^{\circ} \mathrm{C}$ foamed scaffolds (derived from four foams each).

Table 6. Foam structure analyses-derived $d_{\text {median }}$ and $s t_{\text {mean }}$ of $5^{\circ} \mathrm{C}$ and $40{ }^{\circ} \mathrm{C}$ foamed Freeze Foams.

\begin{tabular}{|c|c|c|c|c|c|c|}
\hline Sample & $d_{\text {median }}(\mu \mathrm{m})$ & Mean $(\mu \mathrm{m})$ & $\mathrm{SD}(\mu \mathrm{m})$ & $s t_{m e a n}(\mu \mathrm{m})$ & Mean $(\mu \mathrm{m})$ & $\operatorname{SD}(\mu \mathrm{m})$ \\
\hline $5{ }^{\circ} \mathrm{C} \_1$ & 226 & \multirow{5}{*}{231} & \multirow{4}{*}{5} & 219 & \multirow{4}{*}{215} & \multirow{4}{*}{6} \\
\hline $5^{\circ} \mathrm{C} \_2$ & 230 & & & 208 & & \\
\hline $5{ }^{\circ} \mathrm{C} \_3$ & 236 & & & 221 & & \\
\hline $5{ }^{\circ} \mathrm{C} \_4$ & 234 & & & 212 & & \\
\hline $40^{\circ} \mathrm{C} \_1$ & 724 & & \multirow{4}{*}{43} & 257 & \multirow{4}{*}{269} & \multirow{4}{*}{10} \\
\hline $40^{\circ} \mathrm{C} \_2$ & 711 & \multirow{3}{*}{728} & & 281 & & \\
\hline $40^{\circ} \mathrm{C} \_3$ & 789 & & & 266 & & \\
\hline $40^{\circ} \mathrm{C}_{-} 4$ & 690 & & & 271 & & \\
\hline
\end{tabular}

Figure 9 details the pore size distribution (left) and strut thickness distribution (right) of the obtained Freeze Foams. With regard to the pore size distribution, the $5{ }^{\circ} \mathrm{C}$ Freeze Foams feature a monomodal distribution with a maximum peak around $230 \mu \mathrm{m}$. The $40{ }^{\circ} \mathrm{C}$ Freeze Foams likewise feature a mainly monomodal distribution with the main peak around $800 \mu \mathrm{m}$ and a small peak at around $160 \mu \mathrm{m}$. The large foam cells are suggested to have formed by strong coalescence; the small pores probably represent only slightly coalesced foam cells. In general, $40^{\circ} \mathrm{C}$ foamed structures exhibit much wider distribution with small pores $(30-200 \mu \mathrm{m})$. They are less in abundance compared to the $5{ }^{\circ} \mathrm{C}$ foamed Foams, because destabilizing effects (e.g., coalescence and Ostwald ripening) cause them to become larger during the foaming. This behavior is due to the lower viscosity of the suspension (see Figure 5). The width of both progressions furthermore indicates a certain heterogeneity in pore morphology, which is higher when foaming at $40^{\circ} \mathrm{C}$.

With regard to the strut thickness distribution, the $5^{\circ} \mathrm{C}$ Freeze Foams feature a slightly narrower distribution than the $40{ }^{\circ} \mathrm{C}$ foams. For $40{ }^{\circ} \mathrm{C}$ foams, the standard deviation of the relative abundance is much higher, which indicates that the foam structure is less reproducible than that of $5^{\circ} \mathrm{C}$ foams. Nevertheless, it can be stated that the strut thickness in $5^{\circ} \mathrm{C}$ foams is slightly thinner.

Table 6 shows the resulting mean value of the median equivalent diameter $d_{\text {median }}$ and the strut thickness $s t_{\text {mean }}$. Obviously, foaming $5{ }^{\circ} \mathrm{C}$ tempered suspensions results in much smaller pores than foaming $40^{\circ} \mathrm{C}$ tempered suspensions. Therefore, we assess the initial temperature at the beginning of the Freeze Foaming as a crucial influencing factor for the mean value $d_{\text {median }}$. In addition, $40{ }^{\circ} \mathrm{C}$ foamed samples show a higher standard deviation, which correlates with a lower reproducibility tendency (see Table 2). With regard to the strut thickness, there are only minor differences between the 
two foams compared to the differences in pore size. The thinner struts of $5{ }^{\circ} \mathrm{C}$ foams $(215 \mathrm{vs} .269 \mu \mathrm{m})$ correlate with the higher porosity value (see Tables 4 and 5).

\subsubsection{Direction-Dependent Foam Cell Volume Analyses}

Figures 10 and 11 show the graphical analyses of 5 and $40{ }^{\circ} \mathrm{C}$ foamed suspensions. The variation in progression shows heterogeneity in both sets of Freeze Foams (four cellular structures each). The slice images show individual foam morphologies at particular foam height $z$ in the foaming direction and perpendicular to the foaming direction. Small pores correspond to blue, large pores to red. The averaged foam cell volume is based on three-dimensional calculation, as detailed in Section 2. Figure 10 showcases the specific Freeze Foam " $5{ }^{\circ} \mathrm{C}_{-} 1$ " and Figure 11 the Freeze Foam " $40{ }^{\circ} \mathrm{C} \_3$ ". In the foaming direction (analyzed from bottom to top), $5^{\circ} \mathrm{C}$ foamed structures show a certain variability of foam cell volume $V_{\mathrm{fc}}$ and, therefore, inhomogeneity. It is obvious that the bottom section features larger foam cells (around $z=2-5$ ) than the top (around $z=10-14$ ) (Figure 10A). We suggest two reasons: one is the faster drying at the top compared to the bottom and the second is faster freezing at the top compared to the bottom. In both cases the semi-liquid suspension inhibits bubble growth by drying out and/or freezing. Perpendicular to the foaming (Figure 10B), one side mainly features large foam cells, suggesting border effects, probably due to the high viscosity of the $5{ }^{\circ} \mathrm{C}$ tempered suspensions resulting in air pockets during the filling procedure.
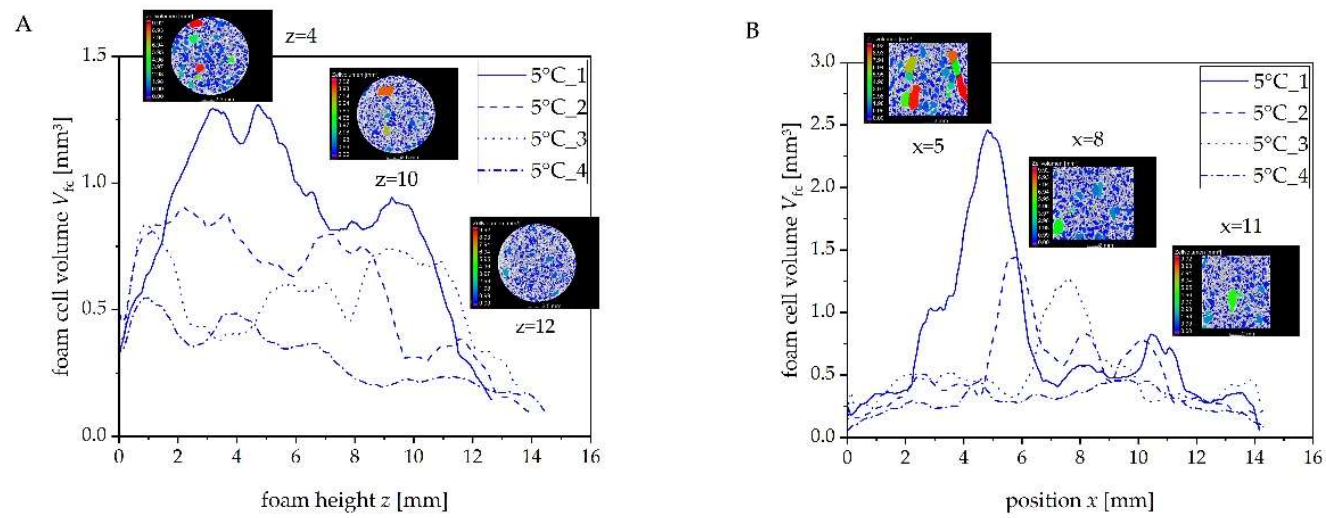

Figure 10. Location-dependent foam cell volume $V_{\mathrm{fc}}$ of $5{ }^{\circ} \mathrm{C}$ foamed suspension (A) foaming direction analyzes; (B) perpendicular to foaming direction.
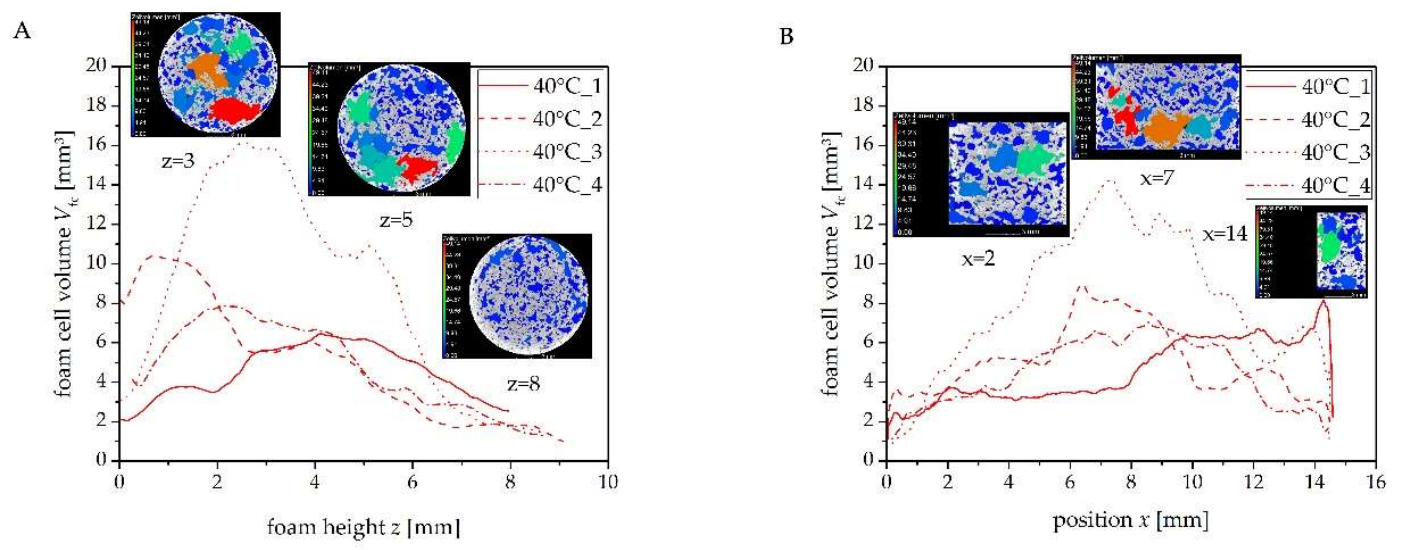

Figure 11. Location-dependent foam cell volume $V_{\mathrm{fc}}$ of $40{ }^{\circ} \mathrm{C}$ foamed suspension: (A) foaming direction analyses; (B) perpendicular to foaming direction.

Observing the $40{ }^{\circ} \mathrm{C}$ foamed structures (Figure 11A), similar to the $5{ }^{\circ} \mathrm{C}$ foams, a majority of large pores becomes obvious within the bottom section of the selected Freeze Foams in the direction 
of foaming (Figure 11A). Perpendicular to the foaming direction large pores are mainly found in the center of selected Freeze Foams (Figure 11B).

By determining the location-dependent foam cell's volume $V_{\mathrm{fc}}(z)$ in the corresponding foaming plane we were able to calculate $V_{\text {fca }}$, the specific arithmetic Freeze Foam cell's average value (Equation (4); Figure 4). A high $V_{\text {fca }}$ corresponds to a large variability in foam cell volume-a heterogeneous foam structure; a low $V_{\text {fca }}$ corresponds to a more homogeneous pore morphology.

Tables 7 and 8 summarize the calculated values for Freeze Foams foamed at $5{ }^{\circ} \mathrm{C}$ and $40{ }^{\circ} \mathrm{C}$, respectively. By comparing the average $V_{f c a}$ in both analysis directions and in accordance with Figures 7 and 8 , we observe that $5{ }^{\circ} \mathrm{C}$ foams result in much more homogeneous structures than $40{ }^{\circ} \mathrm{C}$ foams. Furthermore, in accordance with Figure $10 \mathrm{~A}, \mathrm{~B}, 5^{\circ} \mathrm{C}$ foamed Freeze Foams are more homogeneous in the direction of the foaming than perpendicular to it (Table 7, $V_{\text {fca_average }}=0.19 \mathrm{vs}$. 0.37). However, these findings need to be regarded critically because the SD constitutes approximately $50 \%$ of the mean value. This deviation is likely the result of the filling procedure, which causes boundary effects (as stated before) and is not due to the process itself.

Table 7. Arithmetic foam cell's volume of Freeze Foams foamed at $5{ }^{\circ} \mathrm{C}$.

\begin{tabular}{|c|c|c|c|c|c|c|c|}
\hline \multirow[b]{2}{*}{ Sample } & & \multicolumn{6}{|c|}{$V_{\mathrm{fca}}$} \\
\hline & & $5^{\circ} \mathrm{C} \_1$ & $5{ }^{\circ} \mathrm{C} \_2$ & $5^{\circ} \mathrm{C} \_3$ & $5{ }^{\circ} C_{-} 4$ & $\mathrm{~V}_{\text {fca_average }}$ & $S D_{\text {Vfca }}$ \\
\hline Analyses direction & Foaming direction & 0.28 & 0.24 & 0.13 & 0.10 & 0.19 & 0.09 \\
\hline
\end{tabular}

Table 8. Arithmetic foam cell's volume of Freeze Foams foamed at $40{ }^{\circ} \mathrm{C}$.

\begin{tabular}{|c|c|c|c|c|c|c|c|}
\hline \multirow[b]{2}{*}{ Sample } & & \multicolumn{6}{|c|}{$V_{\text {fca }}$} \\
\hline & & $40^{\circ} \mathrm{C} \_1$ & $40^{\circ} \mathrm{C} \_2$ & $40^{\circ} \mathrm{C} \_3$ & $40^{\circ} C_{-} 4$ & $V_{\text {fca_average }}$ & $S D_{\text {Vfca }}$ \\
\hline ion & Foaming direction & 1.17 & 2.57 & 4.55 & 1.95 & 2.56 & 1.44 \\
\hline
\end{tabular}

In contrast to $5{ }^{\circ} \mathrm{C}$ foamed structures, $40^{\circ} \mathrm{C}$ Freeze Foams are less homogeneous when considered in the direction of foaming (Table $8, V_{\text {fca_average }}=2.56$ vs. 1.86 ). The abovementioned tendency of faster drying out and freezing at the top section of foams is more prominent because of an increased water vapor partial pressure leading to increased water evaporation. Lower viscosity results in less disturbing boundary effects (air pockets due to filling).

We assess the new findings, i.e., $5^{\circ} \mathrm{C}$ Freeze Foams being more homogeneous than $40{ }^{\circ} \mathrm{C}$ Freeze Foams, as adequately proven by our $\mathrm{CT}$ evaluations.

\subsection{Microstructure Analyses of Obtained Freeze Foams}

For evaluating the micropores of obtained HAp Freeze Foams, SEM analyses were conducted. Figures 12 and 13 display the fracture analyses and ion-polished microstructure analyses, respectively, of the cellular structures foamed at $5{ }^{\circ} \mathrm{C}$.

With regard to Figure 12, a mix of different pore sizes $(100-600 \mu \mathrm{m})$ can be observed. The Freeze Foam's struts are filled and highly microporous. The side view shows the foam cell's orientation in the direction of the foaming (bottom to top). Also, the cell walls feature microporosity. These small pores reflect the cryogenic texture, which is the residue of sublimated ice crystals (process induced as stated in Section 1).

The microstructural images in Figure 13 also present a mix of different pore sizes. These lie between 100 and $2000 \mu \mathrm{m}$ and vary between spherical and elongated shape. Due to the low suspension temperature, foam destabilizing effects like Ostwald ripening, coalescence or drainage were kept to a minimum, although some pores already show a beginning coalescence. The microporous struts exhibit some denser regions. Possible reasons may be: inhomogeneous distribution of water in cell walls or 
(visualizing a 3D volumetric view), existing neighboring struts where parts are denser, and neighboring cells where struts are more porous.

Figures 14 and 15 display the fracture analyses and ion-polished microstructure analyses, respectively, of the cellular structures foamed at $40{ }^{\circ} \mathrm{C}$. In contrast to the images above, the Freeze Foam is highly heterogeneous in structure. Large voids rather than well-shaped pores are connected by thick and microporous filled struts. Again, cryogenic texture along the cell walls can be observed. The microstructural images (Figure 15) only show a few small pores in the region of $200 \mu \mathrm{m}$. The majority are large voids or irregular shaped pores. Like the Freeze Foams obtained from a $5{ }^{\circ} \mathrm{C}$ tempered suspension, the $40{ }^{\circ} \mathrm{C}$ foamed Freeze Foam's microporous struts also show denser and more porous regions, likely being subject to the same occurrences mentioned above.
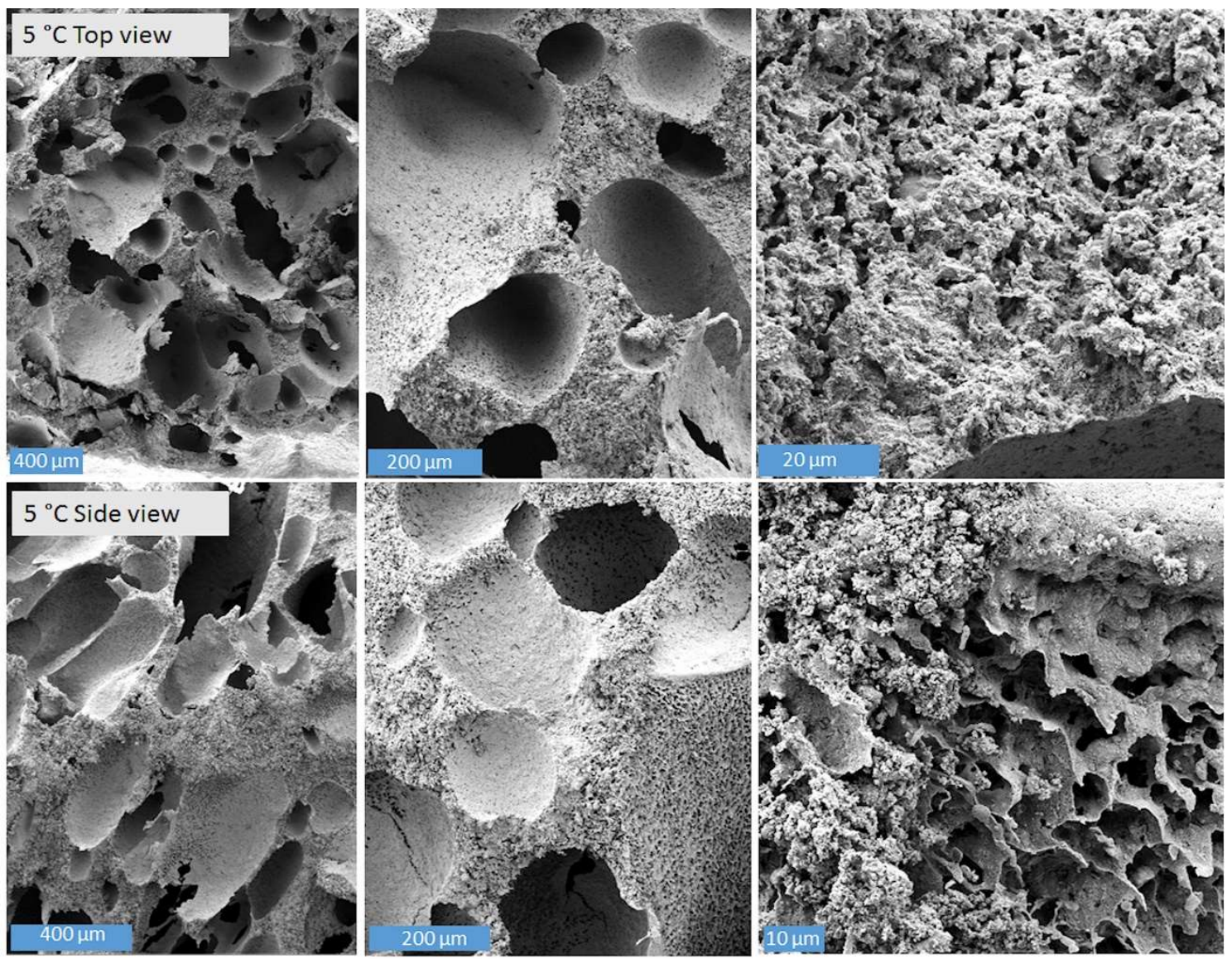

Figure 12. Fracture SEM images of HAp Freeze Foams foamed at $5{ }^{\circ} \mathrm{C}$. 

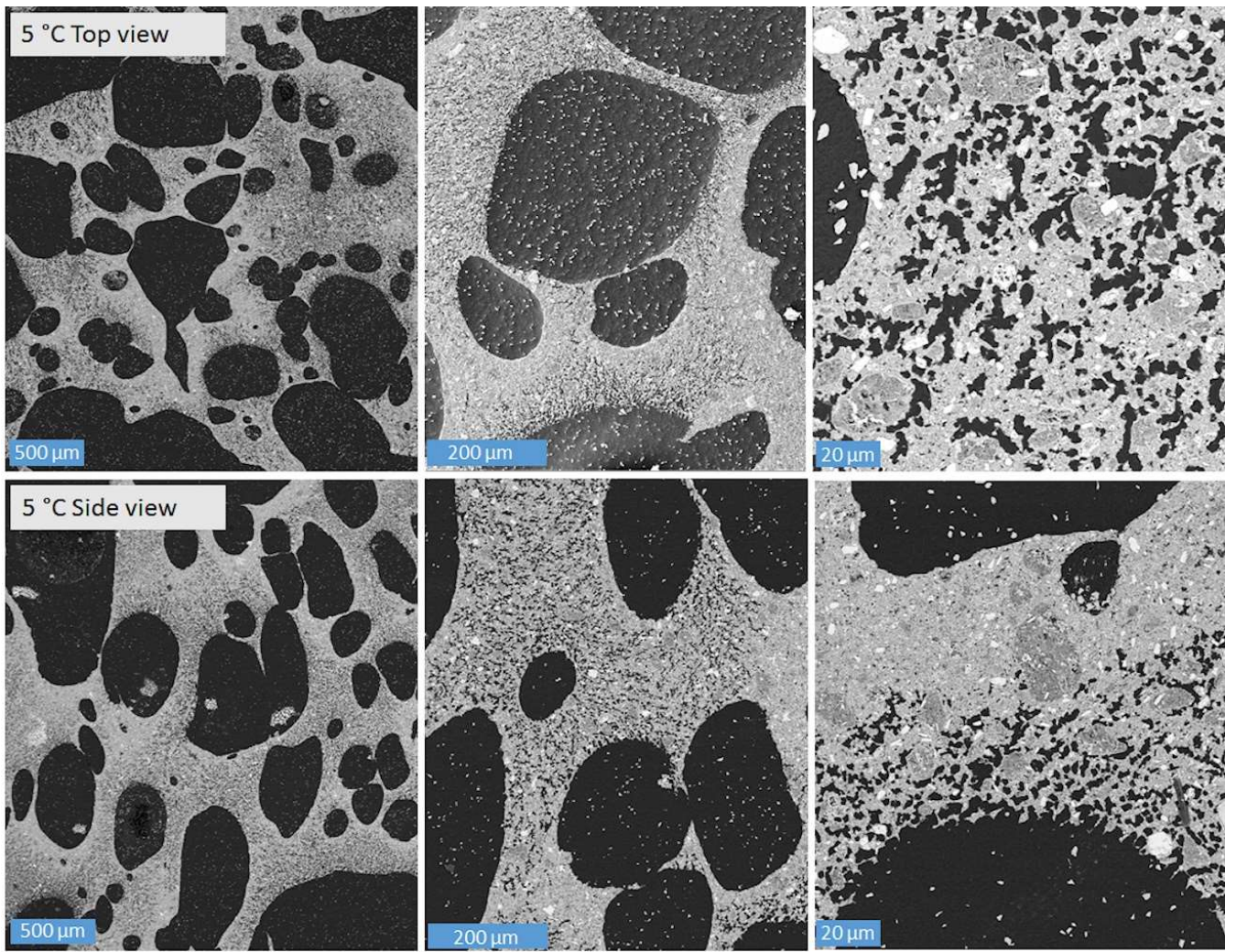

Figure 13. Microstructural SEM images of HAp Freeze Foams foamed at $5{ }^{\circ} \mathrm{C}$.
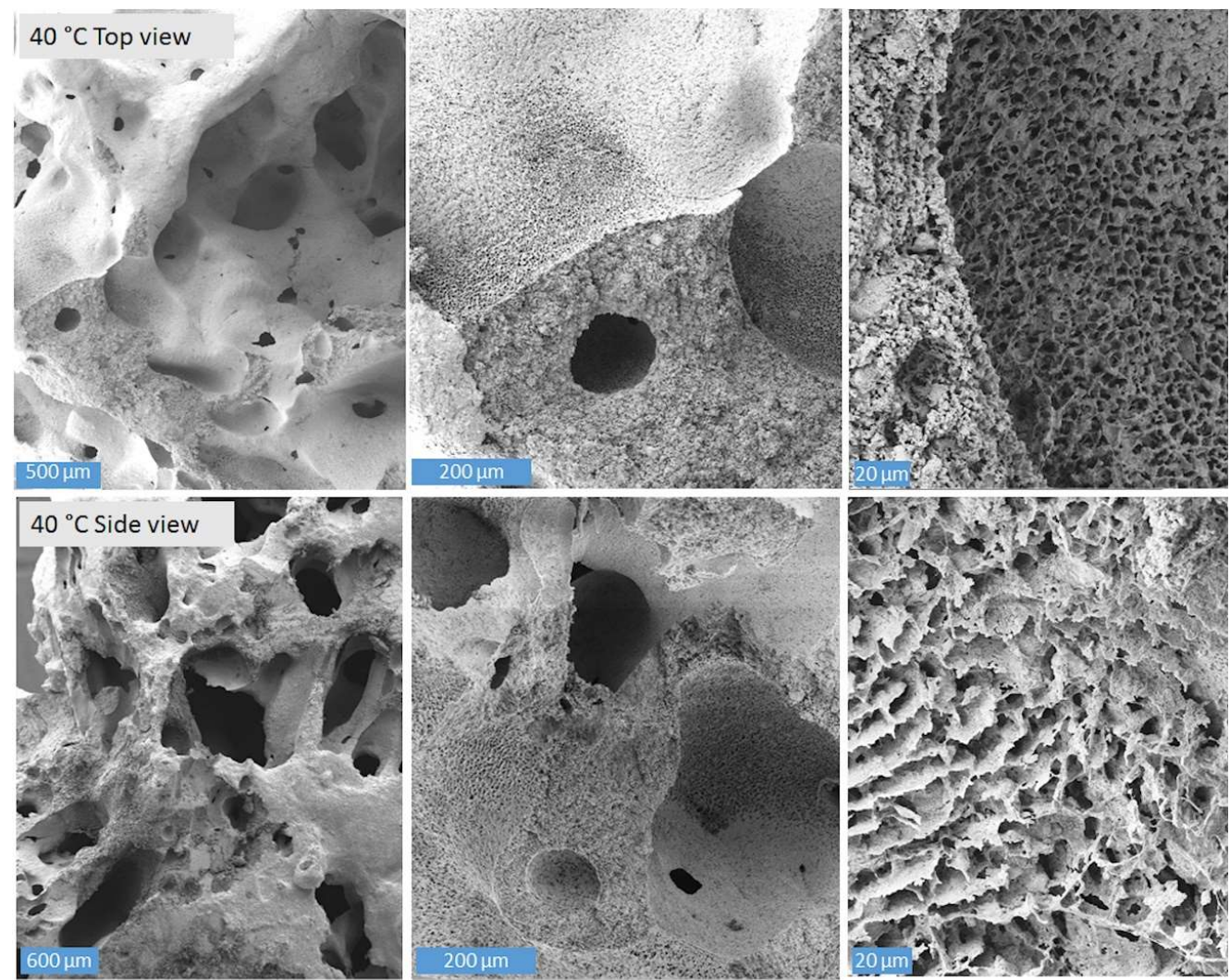

Figure 14. Fracture SEM images of HAp Freeze Foams foamed at $40^{\circ} \mathrm{C}$. 

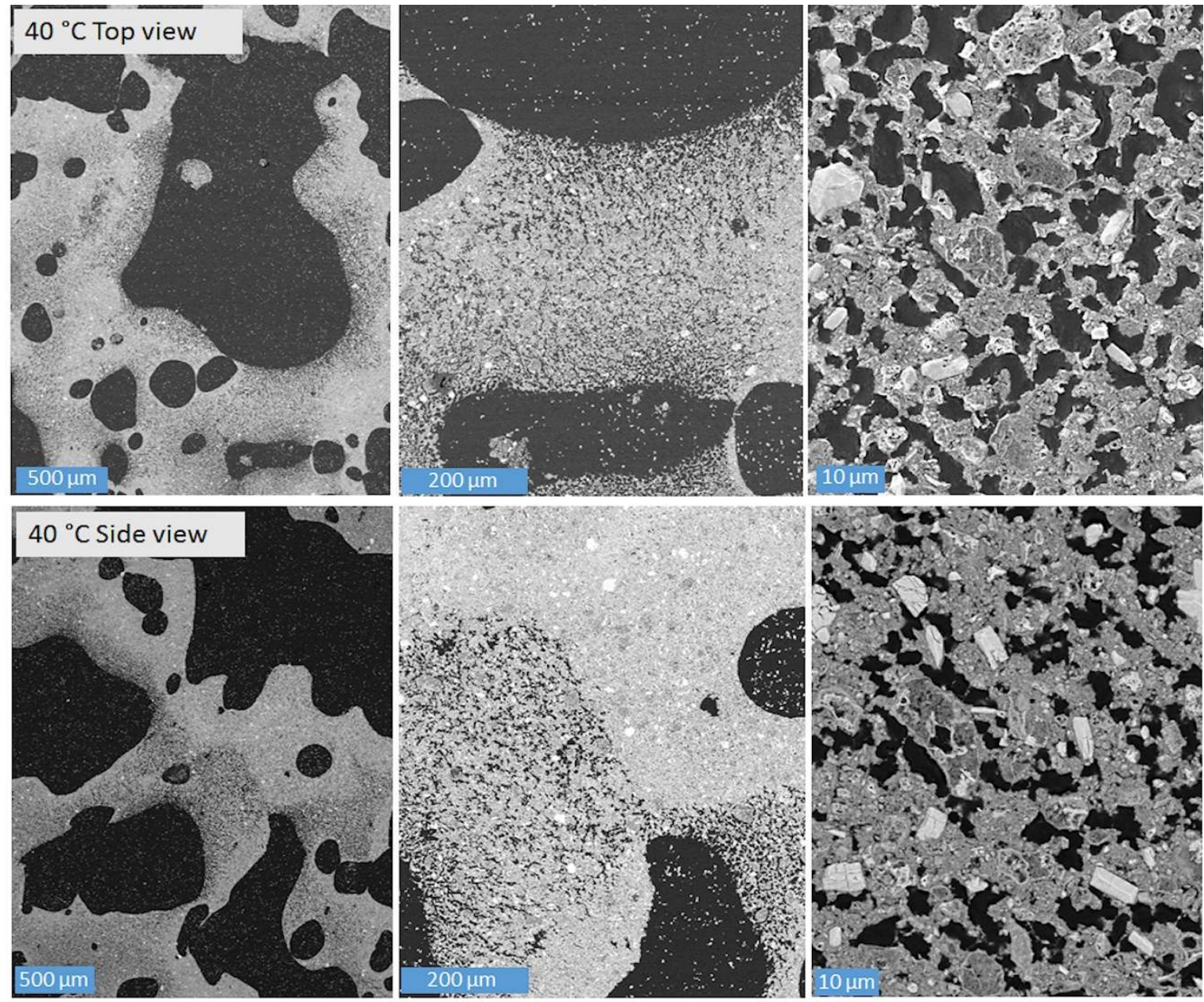

Figure 15. Microstructural SEM images of HAp Freeze Foams foamed at $40{ }^{\circ} \mathrm{C}$.

\section{Conclusions and Outlook}

We succeeded in manufacturing reproducible Freeze Foams (by geometrical porosity) that appear stable when foamed with 5 and $40{ }^{\circ} \mathrm{C}$ tempered suspensions. CT-derived quantitative analyses of the pore morphology as well as SEM images show that pore size, shape and distribution are not reproducible and vary significantly at this stage. Proven by the newly introduced specific arithmetic Freeze Foam cell's average parameter $V_{\mathrm{fca}}$, this especially applies with regard to cellular Freeze Foams foamed at $40{ }^{\circ} \mathrm{C}$. Nevertheless, the presented findings strongly indicate that the foaming of $5{ }^{\circ} \mathrm{C}$ tempered suspensions might lead to homogeneous pore morphology. One of the main findings of the first period was that Freeze Foam's pores are becoming larger and more irregular the faster the pressure reduction rate [9]. Therefore, with regard to the aim of achieving a homogeneous pore structure, we now identify the temperature and the pressure reduction rate as significant process parameters that have to be controlled. In follow-up research we will combine these factors and evaluate their effect on the foam's structure.

We also identified specific main regions of foaming activity by calculating the foaming degree and rate. Follow-up research will deal with targeted foaming control by deliberately adding pressure holds within these regions.

Mold-related issues (geometry, material) and the filling procedure (the possibility of enclosed air in the suspension) will be further points of interest since they have an effect on the pore structure of obtained Freeze Foams and have to be minimized. In that regard, so far we cannot transfer the exact findings/principles of this contribution to the manufacturing of larger structures. However, 
considering and systematically combining all of these found adjusting screws, we are getting closer to reproducible and homogeneous pore morphologies manufactured via Freeze Foaming.

As stated in Section 1, this contribution mainly reports on green-state Freeze Foams. This is useful and necessary in terms of evaluating how suspension and foaming process affect the resulting pore structure. Sintered foams, though, will play a role in applications and, therefore, are subject to subsequent analyses and comparison to their green-state condition.

Author Contributions: M.A. is the DFG-funded project's editor and manager, scientifically conceiving, guiding and supervising experiments and evaluations as well as writing the manuscript; project editor D.W. mainly is working on the scientifically relevant questions concerning the experiments and significantly contributed to the evaluations and analyses; N.K. and J.A., both project editors, worked on the numerous experiments presented in this contribution; J.M. and T.B. are the DFG project's manager and editor from the TU-DD ILK; T.M., A.M., and M.G. helped with higher-ranked issues and questions.

Funding: This work has been funded by DFG (Grant number 310892168) and the Fraunhofer Society.

Acknowledgments: The authors very much appreciate the support and assistance of David Werner and Nils Kaube, as well as the project partner's TUD-ILK assistance, work and many enlightening hours together.

Conflicts of Interest: The authors declare no conflict of interest. The founding sponsors had no role in the design of the study; in the collection, analyses, or interpretation of data; in the writing of the manuscript, and in the decision to publish the results.

\section{References}

1. Du Pont de Nemours, E.I. Colloidal Silica Foam. UK Patent 1175760, 21 December 1967.

2. Wood, L.; Messina, P.; Frisch, C. Method of Preparing Porous Ceramic Structures by Firing a Poplyurethane Foam that Is Impregnated with Inorganic Material. U.S. Patent 3833386, 3 September 1974.

3. Eckert, K.-L.; Mathey, M.; Mayer, J.; Homberger, F.; Thomann, P.; Groscurth, P.; Wintermantel, E. Preparation and in vivo testing of porous alumina ceramics for cell carrier applications. Biomaterials 2000, 21, 63-69. [CrossRef]

4. Schwartzwalder, K.; Somers, A. Method of Making Porous Ceramics Articles. U.S. Patent 3090094, 21 May 1963.

5. Komarneni, S.; Pach, L.; Pidugu, R. Porous $\alpha$-alumina ceramics using bohemite and rice flour. Mater. Res. Soc. Symp. Proc. 1995, 371, 285-290.

6. Lopes, R.A.; Segadaes, A.M. Microstructure, permeability and mechanical behavior of ceramic foams. Mater. Sci. Eng. 1996, 209, 149-155. [CrossRef]

7. Moritz, T. Lightweight Green Compact and Molded Article Made of a Ceramic and/or Powder-Metallurgical Material, and the Method for the Production of Thereof. Patent DE102008000100, 18 January 2008.

8. Ahlhelm, M. Gefrierschäume-Entwicklung von Zellularen Strukturen für Vielfältige Anwendungen/Freeze Foams-Development of Cellular Structures for Various Applications; Schriftenreihe Kompetenzen in Keramik; Fraunhofer, I.K.T.S., Alexander, M., Eds.; Fraunhofer Verlag: Dresden, Germany, 2016; Band 32; ISBN 978-3-8396-0977-4.

9. Ahlhelm, M.; Werner, D.; Maier, J.; Abel, J.; Behnisch, T.; Moritz, T.; Michaelis, A.; Gude, M. Evaluation of the pore morphology formation of the Freeze Foaming process by in situ computed tomography. J. Eur. Cerm. Soc. 2018, 38, 3369-3378. [CrossRef]

10. Deville, S.; Saiz, E.; Tomsia, A.P. Freeze casting of hydroxyapatite scaffolds for bone tissue engineering. Biomaterials 2006, 27, 5480-5489. [CrossRef] [PubMed]

11. Deville, S. Freeze-Casting of Porous Biomaterials: Structure, Properties and Opportunities. Materials 2010, 3 , 1913-1927. [CrossRef]

12. Ahlhelm, M.; Fruhstorfer, J.; Moritz, T.; Michaelis, A. The Manufacturing of Lightweight Refractories by Direct Freeze Foaming Technique. Interceram 2011, 60, 394-399.

13. Ahlhelm, M.; Moritz, T. Synthetic Bone Substitute Material and Method for Producing the Same. European Patent EP2682137A3, 1 February 2013.

14. Ahlhelm, M.; Moritz, T. Herstellung eines biokompatiblen Hydroxylapatit- $\mathrm{ZrO}_{2}-\mathrm{Hybridschaums} \mathrm{über} \mathrm{die}$ Methode der Gefrier-Direktschäumung. In Schriftenreihe Werkstoffe und Werkstofftechnische Anwendungen; Wielage, B., Ed.; Deutsche Gesellschaft für Materialkunde e.V. DGM: Chemnitz, Gemany, 2011; Volume 41. 
15. Ahlhelm, M.; Gorjup, E.; von Briesen, H.; Moritz, T.; Michaelis, A. Freeze-foaming-a promising approach to manufacture strength enhanced ceramic cellular structures allowing the ingrowth and differentiation of human mesenchymal stem cells. In Proceedings of the International Conference MiMe-Materials in Medicine (1st edition MIME), Faenza, Italy, 8-11 October 2013.

16. Ahlhelm, M.; Günther, P.; Scheithauer, U.; Schwarzer, E.; Günther, A.; Slawik, T.; Moritz, T.; Michaelis, A. Innovative and novel manufacturing methods of ceramics and metal-ceramic composites for biomedical applications. J. Eur. Cerm. Soc. 2016, 12, 2883-2888. [CrossRef]

17. Ahlhelm, M.; Schwarzer, E.; Scheithauer, U.; Moritz, T.; Michaelis, A. Novel ceramic composites for personalized 3D-structures. J. Ceram. Sci. Technol. 2017, 8, 91-100.

18. Routschka, G. Feuerfeste Werkstoffe; Vulkan-Verlag: Essen, Gemany, 1997; p. 2.

19. Sepulveda, P.; Bressiani, A.H.; Bressiani, J.C.; Meseguer, L.; König, B., Jr. In vivo evaluation of hydroxyapatite foams. J. Biomed. Mater. Res. 2002, 62, 587-592. [CrossRef] [PubMed]

20. Rueger, J.M.; Linhart, W.; Sommerfeldt, D. Biologische Reaktionen auf Kalziumphosphatkeramik-Implantationen. Tierexperimentelle Ergebnisse. In Der Orthopäde; Springer-Verlag: Berlin/Heidelberg, Germany, 1998; Volume 27, pp. 89-95.

21. Best, S.M.; Porter, A.E.; Thiana, E.S.; Huang, J. Bioceramics: Past, present and for the future. J. Eur. Cerm. Soc. 2008, 28, 1319-1327. [CrossRef]

22. Hutmacher, D.W. Scaffolds in tissue engineering bone and cartilage. Biomaterials 2000, 21, $2529-2543$. [CrossRef]

23. Karageorgiou, V.; Kaplan, D. Porosity of 3D biomaterial scaffolds and osteogenesis. Biomaterials 2005, 26, 5474-5491. [CrossRef] [PubMed]

24. Wegst, U.G.K. Biomaterials by freeze casting. Philos. Trans. R. Soc. A 2010, 368, 2099-2121. [CrossRef] [PubMed]

25. Nakayama, H. Nondestructive Microstructural Analysis of Porous Bioceramics by Microfocus X-ray Computed Tomography ( $\mu \mathrm{CT})$ : A Proposed Protocol for Standardized Evaluation of Porosity and Interconnectivity Between Macro-pores. J. Nondestruct. Eval. 2011, 30, 71-80. [CrossRef]

26. Peyrin, F. Evaluation of bone scaffolds by micro-CT. Osteoporos. Int. 2011, 22, 2043-2048. [CrossRef] [PubMed]

27. Jones, J.R.; Poologasundarampillai, G.; Atwood, R.C.; Bernard, D.; Lee, P.D. Non-destructive quantitative 3D analysis for the optimisation of tissue scaffolds. Biomaterials 2007, 28, 1404-1413. [CrossRef] [PubMed]

28. Van Lenthe, G.H.; Hagenmüller, H.; Bohner, M.; Hollister, S.J.; Meinel, L.; Müller, R. Nondestructive micro-computed tomography for biological imaging and quantification of scaffold-bone interaction in vivo. Biomaterials 2007, 28, 2479-2490. [CrossRef] [PubMed]

29. Ducheyne, P.; Qiu, Q. Bioactive ceramics: The effect of surface reactivity on bone formation and bone cell function. Biomaterials 1999, 20, 2287-2303. [CrossRef]

30. Shors, E.C.; Holmes, R.E. Porous hydroxyapatite. In An Introduction to Bioceramics. Advanced Series in Ceramics; Hench, L.L., Wilson, J., Eds.; World Scientific Publishing Co.: Singapore, 1993; Volume 1, pp. 181-198.

31. Liu, D.M. Porous hydroxyapatite bioceramics. In Key engineering Materials; Liu, D.M., Ed.; Trans Tech Publications: Uetikon-Zurich, Switzerland, 1996; Volume 115, pp. 209-232.

32. VGSTUDIO. Available online: https://www.volumegraphics.com/de/produkte/vgstudio.html (accessed on 2 May 2018).

33. DIN EN ISO 4287. Geometrical Product Specifications (GPS)—Surface Texture: Profile Method-Terms, definitions and surface texture parameters (ISO 4287:1997 + Cor 1:1998 + Cor 2:2005 + Amd 1:2009); International Organization for Standardization: Geneva, Switzerland, 1997; pp. 1-24.

(C) 2018 by the authors. Licensee MDPI, Basel, Switzerland. This article is an open access article distributed under the terms and conditions of the Creative Commons Attribution (CC BY) license (http://creativecommons.org/licenses/by/4.0/). 